\title{
Estado e catching up: 40 anos de mutação estratégica estatal e seus resultados ao sistema nacional de inovação da China
}

\author{
João Leonardo Akihito Mitsuse* \\ Pablo Felipe Bittencourt**
}

\begin{abstract}
Resumo
O processo de catching up tecnológico chinês é o mais recente e instigante caso do mundo. $\mathrm{O}$ artigo parte do princípio neoshumpeteriano em que a particularidade do processo importa como referência à promoção de adaptações a outras estratégias nacionais. A causalidade entre ações estatais e capacidade inovadora é induzida no artigo por meio da análise evolutiva das duas dimensões. O que inclui um processo de tentativas e erros que se inicia com a cópia do modelo de planejamento soviético até os avanços mais recentes de seus sistema de ciência e tecnologia, passando pela mutação na forma de organização empresarial, incluindo a participação estatal na estrutura decisória das firmas locais e as regras em prol da absorção ativa de tecnologia estrangeira. A conclusão enfatiza a intencionalidade e a eficácia do planejamento e, por consequência, rejeita instituições neoclássicas como recomendação a países menos desenvolvidos.
\end{abstract}

Palavras chave: sistema nacional de inovações chinês; estratégia estatal; China.

\section{State and catching up: 40 years of state strategic mutation and its results to the nacional innovation system in China}

\begin{abstract}
The Chinese technological catching up process is the most recent and exciting case in the world. The article starts from the neoshumpeterian principle and the particularity that the process is important as a reference to the promotion of adaptations to other national strategies. The causality between state actions and innovative capacity is induced in the article by an evolutive review of the two dimensions, which includes a process of trial and error that begins with the copy of the Soviet planning model, until the most recent advances of its science and technology system, undergoing a mutation in the form of business organization, including state participation, decision-making structure of local firms and rules in favor of the active absorption of foreign technology. The conclusion emphasizes the intentionality and effectiveness of planning and, consequently, rejects neoclassical institutions as a recommendation to less developed countries.
\end{abstract}

Key words: chinese national system of innovation; state-owned strategy; China.

JEL: O33

\footnotetext{
*Graduado em Relações Internacionais pela Universidade Federal de Santa Catarina (UFSC). Email: jlamitsuse@gmail.com

**Prof. Dr. do Departamento de Economia e Relações Internacionais da Universidade Federal de Santa Catarina (UFSC). E-mail: pablofelipe.bittencourt@gmail.com
} 


\section{Introdução}

A compreensão sobre o sucesso de um Sistema Nacional de Inovação (SNI) sempre encontra peculiaridades históricas. No caso chinês, de maior sucesso recente, um dos maiores desafios à investigação não consiste apenas na ação estatal centralizada e não democrática do país, que pode resultar na falta de informações, mas envolve algo mais profundo, como nosso próprio enraizamento social, nos levando a uma visão ocidental das coisas, que é potencialmente limitadora da capacidade de reconhecer os valores intrínsecos às particularidades do caso. Não obstante, reconhecer essa fraqueza não impede que relações de causa e efeito possam ser sugeridas como parte de uma narrativa analiticamente bem orientada, nesse caso, pela perspectiva de Sistemas Nacionais de Inovação.

É com essa modéstia que esse artigo objetiva relacionar a evolução da capacidade inovadora revelada pelo SNI chinês à mudança nas formas de atuação estatal nos últimos 40 anos. A opção pelo foco na evolução das capacidades empresariais e dos tradicionais centros de ciência e tecnologia (universidades, e centros tecnológicos) justifica-se por serem os principais locus de realização de pesquisa e desenvolvimento (P\&D), o que serve como bom indicador de um processo de catching up tecnológico (KIM, 2006), assim como sugere inovações de maior grau (JENSEN, et.al., 2007 e BITTENCOURT, BRITO e GIGLIO, 2016).

Para isso, além da bibliografia específica sobre os Sistemas Nacionais de Inovação e sobre o desenvolvimento estatal, produtivo, tecnológico e científico chinês, foram explorados discursos oficiais de líderes políticos, documentos oficiais de entidades industriais e estatísticas complementares.

O trabalho está dividido em seis seções. Além dessa introdução, na segunda são definidas as bases teóricas/analíticas e a visão de mundo utilizadas como pano de fundo à análise. Nas seções subsequentes são expostas: a) as transformações históricas da estratégia estatal chinesa e; b) a posterior análise de suas implicações na produção e na capacidade inovativa do país. Especificamente, na terceira seção é feita uma recapitulação histórica da economia centralizada, enquanto a quarta, discorre sobre a mudança estratégica pós 1978, a quinta sobre os avanços no século XXI e a última seção, faz uma breve conclusão. 


\section{Sistemas nacionais de inovação e as estratégias de desenvolvimento econômico}

O papel do Estado no direcionamento de uma estratégia industrial rumo ao catching up não é elemento novo (List, 1989 e Freeeman, 2006), mas vem recebendo diferentes e interessantes contribuições contemporâneas, como em Rodrick (2004, 2007), Andreoni (2016) e Andreoni e Chang (2019). Para Perez (2001), uma estratégia tecnológica é condição vital ao catching up, enquanto que Mazzucato (2014) mostrou que é o papel ativo e paciente do Estado, fornecendo grandes somas de recursos por longos períodos, o que explica o desenvolvimento de muitas das tecnologias mais promissoras do atual paradigma.

Se, por um lado, isso significa que uma estratégia ativa do Estado pode ser essencial à melhora da capacidade de um território de gerar e gerir a mudança tecnológica em seus domínios, o que pode influenciar o sentido e a velocidade de avanço de fronteiras tecnológicas de um paradigma, por outro lado, o próprio processo de transição e firmamento de um novo paradigma leva à necessidade de adaptação institucional estatal, o que remete ao valor de contar com uma estrutura institucional ativa.

Segundo Perez (1992), no período de mudança de paradigma ocorrem oportunidades tecnológicas, cujos aproveitamentos são influenciados pela adaptabilidade e criatividade institucional existente no país. A capacidade de re-ordenar o aparato institucional pode ser o elemento vital da estratégia não apenas por contribuir à difusão de tecnologias geradas fora, mas, especialmente pela contribuição ao acúmulo paulatino de capacidades tecnológicas, o que pode ser encontrado tanto na adesão ao mercado como na proteção ao mesmo, tanto no fortalecimento da pesquisa básica, como na pesquisa aplicada, no desenvolvimento experimental ou em várias outras formas, dependendo das capacidades acumuladas nas trajetórias tecnológicas em análise.

O referencial analítico de Sistemas Nacionais de Inovação procura dar conta dessas especificidades, partindo de teses neoschumpeterianas que enfatizam a mudança tecnológica endogenamente determinada pelas revoluções tecnológicas capitalistas teorizadas nas ideias de ciclos longos de Schumpeter ou de ondas longas de Perez (2004).

Elemento central dessa concepção é a noção de paradigma tecno-econômico que informa sobre um modelo básico compartilhado pelos agentes da estrutura produtiva em relação à forma como tudo é produzido. Tal formato deriva do processo de difusão das novas tecnologias que dão início a cada revolução. Uma revolução criou os próprios 
departamentos de P\&D na década de 1920, a partir do modelo de produção em série e, mais recentemente a difusão das tecnologias de informação e comunicação (TICs) tem explicado a integração produtiva amplamente discutida sob a ideia de indústria 4.0.

A mudança tecnológica engendrada pelo processo de difusão tecnológica das revoluções aumenta a incerteza em relação ao engajamento em trajetórias tecnológicas mais promissoras por atores de restrito nível de capacidade tecnológica acumulada, em geral, localizados em países em desenvolvimento. Isso reforça o valor da atuação estatal, que no caso dos países que efetivamente realizaram o catching up tecnológico costuma se revelar em diversas dimensões e em formatos particulares.

A perspectiva de Sistemas de Inovação procura dar conta dessas particularidades ao destacar o valor analítico dos mecanismos que induzem os processos de criação de competências, de aprendizagem, acúmulo de conhecimentos e geração e difusão de inovações em diferentes países (LUNDVALL, 2007). O reconhecimento das particularidades foi suficiente para que os esforços de comparação fossem minimizados por muito tempo.

No entanto, alertando para a impossibilidade de uma teoria geral sobre a inovação e reforçando as particularidades institucionais e produtivas nacionais, Edquist e Hommen (2008) oferecem uma concepção subdividida em 10 dimensões comparáveis entre SNIs, a partir dos avanços já alcançados sobre as causas das inovações. Esse artigo tem foco em duas dessas dimensões complementares à identificação da passagem de uma situação de capacidade imitativa para de inovação mais sofisticada, são elas, a capacidade de prover $\mathrm{P} \& \mathrm{D}$, especialmente em engenharia, medicina e ciências naturais, e de construir competências na força de trabalho para serem utilizadas em inovação e P\&D.

Essas dimensões estão estritamente relacionadas pela noção de capacidade de absorção (COHEN; LEVINTHAL, 1990) gerada pela compreensão mútua de problemas, soluções e caminhos de uma determinada trajetória científica e/ou tecnológica. Antes de apresentar as evidências mais recentes da evolução do SNI chinês nessas duas dimensões (seção 5), o "terreno" é preparado ao apresentar características marcantes da transformação da lógica de atuação do Estado em sua relação com o setor produtivo, desde o pós-guerra até 1978 (seção 3) e de 1978 até o início do século XXI (seção 4). 


\title{
3 O embrião da particularidade fundamental: o sistema centralizador não democrático
}

Já defasada por conta dos conflitos da segunda guerra sino-japonesa (1937-1945), a indústria chinesa fora ainda mais limitada pela guerra civil (1946-1949) que culminou na Revolução Socialista. No período, o setor agrícola respondia por $90 \%$ do valor da produção de uma economia cuja renda per capita não chegava a 50 dólares (ZHENG, 2004). Para Lu Zheng (2004), a mudança das regras do jogo, decisiva para o início da mutação dessa situação e que definiram a transição socialista podem ser resumidas em:

\begin{abstract}
1) Confisco da burocrática indústria, das finanças e do comércio capitalista das quatro grandes famílias - Jiang, Song, Kong e Chen - e conversão desse patrimônio em uma economia nacional, representando os interesses do povo de todo o país e permitindo, dessa forma, ao Estado ganhar o controle do suporte vital da economia nacional. 2) Unificação das finanças nacionais e contenção da inflação descontrolada, de modo a criar um ambiente macroeconômico adequado ao desenvolvimento da economia. 3) Realização da reforma agrária, dividindo 120 milhões de acres de terra entre 300 milhões de camponeses, que tinham pouca ou nenhuma terra para arar, mudando uma situação em que $90 \%$ dos camponeses chineses possuíam menos de $30 \%$ da terra arável e liberando-os de uma relação de produção feudal. 4) Encorajamento e apoio ao crescimento da indústria e do comércio capitalista nacionais. O governo pôs a indústria e o comércio capitalista individuais na órbita de uma nova economia democrática, ajudando-os a solucionar dificuldades com matéria-prima, mercado e capital. (ZHENG, 2004, p. 77).
\end{abstract}

A industrialização seguia o planejamento soviético, modelo organizacional marcado pelo poder de decisão e a propriedade dos bens centralizados no Estado, cristalizado no Primeiro Plano Quinquenal de julho de 1955 (BACHMAN, 2006). Foram estabelecidos 156 contratos de construção de instalações com tecnologia soviéticas, a maioria relacionadas à indústria pesada, geração de energia, mineração, refinarias, ferramentarias químicas e mecânicas, além de terem sido criados mais de 400 unidades de pesquisa, inicialmente voltadas para a engenharia reversa (LIU e WHITE, 2001). A denominada "Comissão de Planejamento Estatal" era responsável pelo controle da alocação de recursos e supervisão organizacional de todo o processo.

A organização industrial à la URSS fez emergir no SNI chinês milhares de organizações especializadas com fronteiras essencialmente divididas pelo tipo de atividade, por exemplo, as atividades de implementação deveriam ser realizadas especificamente por fábricas, enquanto as de $\mathrm{P} \& \mathrm{D}$ por institutos de pesquisa (que ainda eram subdivididos entre institutos de pesquisa básica e aplicada). A articulação entre as organizações era mediada por comitês industriais, caracterizando o que Lieberthal (1995) 
denominou de "autoritarismo fragmentado", no qual a tomada de decisão fora multicentralizada e o poder distribuído verticalmente e horizontalmente por mandatos definidos por tipo de atividade.

Essa sub-divisão burocrática imprimia um ritmo ineficaz de interação entre os atores tipicamente responsáveis pelos processos de produção e inovação, comparativamente ao que acontecia no ocidente. Muitas vezes, sequer havia proximidade geográfica entre os atores, alocados segundo diferentes critérios, como demandas por emprego das diferentes regiões. Isso resultava em uma limitação auto-imposta aos fluxos de conhecimento tácito, sabidamente aceleradores do progresso técnico.

Além disso, o critério de desempenho era quase que somente quantitativo. Praticamente inexistiam mecanismos governamentais para encorajar as organizações a diferenciar a produção sob suas responsabilidades, o que explica casos como o do “caminhão de liberação", importado da URSS nos anos 50 e que manteve-se em linha de produção sem qualquer alteração por 40 anos. Em outras palavras, não existia incentivos para que as organizações introduzissem, difundissem ou adotassem proativamente quaisquer tipos de novas tecnologias.

Apesar do nome do plano, ele durou até 1958, quando foi lançado o Segundo Plano Quinquenal, caracterizado pela busca obcecada por um alto crescimento econômico e pela adoção de metas de produção impraticáveis. A exemplo de outras economias subdesenvolvidas, a China adotou a política de "siderurgia como elo-chave". Por exemplo, foi requerido pelo governo que a produção de 1958 correspondesse ao dobro da produção de 1957, ou seja, ir de 5,35 milhões de toneladas de aço para 10,7 milhões de toneladas (ZHENG, 2006). O resultado do que deveria ter sido o "Grande Salto" chinês, foi um desastre econômico, debitado na conta do plano centralizado, de grandes calamidades naturais e do cancelamento pela URSS de contratos de projetos com a China.

Na década de 1960, enquanto o governo se dedicava a realinhar a relação entre a agricultura, a indústria leve e a indústria pesada, para a recuperação do crescimento econômico, nos campos político e científico a Revolução Cultural imprimia fortes discordâncias entre pesquisadores e políticos, o que gerou perseguições ideológicas e o fechamento de muitas universidades, além do envio de professores para trabalho em campos e fazendas, resultando na perda de uma geração de pesquisadores (SCHWAAGSERGER, 2007). Mesmo assim, grandes conquistas tecnológicas foram alcançadas no período, como a criação de uma bomba atômica em 1964, uma bomba de hidrogênio em 1967 e o lançamento de satélites nacionais em 1970, o que reforça a preocupação 
governamenal com a capacidade de defender sua forma de gestão de potenciais ameaças externas.

Resumidamente, procurou-se mostrar nesta seção, que a economia centralizada chinesa e os primeiros Planos Quinquenais (herdados da lógica soviética), apesar de envolverem aprendizados tecnológico limitados a projetos de equipamentos soviéticos, foram decisivos à implementação de instituições capazes de sustentar uma estratégia de centralização do poder de decisão. Entre as debilidades dessa tentativa encontra-se a excessiva burocratização das interações, o distanciamento geográfico e a ausência de incentivos à diferenciação de produtos. Uma importante exceção foi o setor militar que passou a dominar a dinâmica tecnológica em armamentos atômicos, o que contribuiu para a consolidação do poder político internacional chinês, revelado, por exemplo, pela participação no Conselho de Segurança das Nações Unidas.

\section{Mutações da esfera produtiva e científica em prol da capacitação tecnológica imitadora: 1978-1995}

Com a morte de Mao Tsé-Tung e a chegada ao poder de Deng Xiaoping em 1976, o pragmatismo político-ideológico passou a sobrepor a ideologia extremista da "Revolução Cultural”. O discurso de 18 de março de 1978 marcava aspectos centrais de uma mudança significativa. Nele o líder condenou duramente as ações tomadas pela "Gangue dos Quatro" (que representava os ideais da "Revolução Cultural"), exaltou a importância da ciência e da tecnologia para o desenvolvimento do país e acenou para a importância do capital estrangeiro ao processo de modernização.

[...] Even though we have a dictatorship of the proletariat, unless we modernize our country, raise our scientific and technological level, develop our productive forces and thus strengthen our country and improve the material and cultural life of our people - unless we do all this, our socialist political and economic system cannot be fully consolidated, and there can be no sure guarantee for the country's security. [...] The key to our modernizations is the modernization of science and technology. (XIAOPING, 1978 apud CHINA, 2019. p. 1-2) ${ }^{1}$.

A compreensão de que o período guardava "an enormous gap between the level of our science and technology and that of the most advance countries (XIAOPING, 1978,

\footnotetext{
${ }^{1} \mathrm{O}$ trecho faz parte do discurso proclamado pelo presidente Deng Xiaoping da China em 18 de março de 1978, durante a Cerimônia de Abertura da Conferência Nacional para a Ciência. O texto oficial completo está disponível em: <english.china.org.cn/english/features/dengxiaoping/103390.ht〉. Acesso em: 28 de outubro de 2019.
} 
apud CHINA, 2019, p. 3), guiou o dito pragmatismo, revelado em políticas voltadas à inserção em uma lógica mercadológica dos processos de produção que incluiam: a gradual descentralização da tomada de decisão em firmas e outras instâncias; a criação de leis específicas estimuladoras de atividades de inovação; o investimento em universidades e institutos de pesquisa e a participação em tratados internacionais relativos a propriedade intelectual, o que não significa que esses últimos tenham sido cumpridos a risca, nem mesmo que estejam sendo hoje (BITTENCOURT; CHIARINI, 2019).

A descentralização das decisões partiu do reconhecimento da ineficiência e da baixa efetividade da economia centralizada. Importante mudança governamental inicial foi a alteração do critério de avaliação de performance da produção das empresas, passando a considerar fatores como retornos sobre ativos investidos, noções de lucratividade e resultados em vendas. Como inovação depende de reconhecimento de mercado e, por definição, não responde estritamente a planejamento para sua ocorrência, a descentralização nas tomadas de decisão passaram a ser mais bem vistas, modificando de forma gradual e muito particular a gestão empresarial chinesa.

No caso das universidades e institutos de pesquisa, os incentivos ao empoderamento da tomada de decisão aconteceram com a junção de duas ações políticas: 1) a permissão da venda ou licenciamento de tecnologias desenvolvidas pelas organizações, além da permissão da condução de contratos de pesquisa e da promoção de serviços de consultoria para outras organizações; e, 2) com a diminuição do suporte financeiro às organizações (LIU; WHITE, 2001). A lógica era a de forçar os institutos de pesquisa a buscarem outras formas de renda e durante este caminho melhorarem sua qualidade e produtividade, pois, em busca de financiamento, deveriam assumir mais responsabilidades sob os problemas dos manufatureiros e dos consumidores finais. Com essas duas políticas, os centros de pesquisa tinham o estímulo para buscar o desenvolvimento (a falta de financiamento direto) e o caminho livre para conquista-lo (a permissão para o relacionamento com outras organizações privadas).

Apesar desses esforços de inovação, as empresas se mantiveram inicialmente com o foco na imitação (BOEING e SANDNER, 2011), o que é esperado, uma vez que a capacidade de inovar é cumulativa. Era necessário tempo para que as empresas chinesas se adequassem aos novos padrões de produção, tanto no quesito de absorção de novas tecnologias, quanto no desenvolvimento de uma mentalidade inovadora. O fluxo de conhecimento necessário à reforma do Sistema Nacional de Inovação chinês dependia de 
um longo tempo de maturação das relações entre os chineses e desses com atores forâneos.

Parte desse esforço cristalizou-se nas Zonas Econômicas Especiais (geralmente localizadas em províncias costeiras). Nelas, foram introduzidas legislações próprias para permitir o estabelecimento de determinados mecanismos capitalistas e o assentamento de capitais e empresas estrangeiras. Essa reinserção da China no sistema internacional fez com que o país passasse a ser chamado de "nação com dois sistemas" (VISENTINI, 2011).

Esse primeiro empuxe de crescimento via exportações esteve assentado no baixo custo da mão de obra. Contudo, com ele iniciou-se um conjunto significativo de ações em prol da capacidade de absorver tecnologia de forma ativa, o que amplia as possibilidades de, efetivamente, gerar mudanças tecnológicas no longo prazo. Esperava-se que joint ventures entre empresas chinesas e estrangeiras contribuíssem para a melhora da performance do sistema de inovação do país, por meio da transferência de tecnologias e de contribuições gerenciais e técnicas. Dessa intencionalidade derivou-se um amplo conjunto de políticas setoriais específicas. Um bom exemplo foi a Política Industrial para a Indústria Automobilística de 1994, que em seu artigo 31, afirmava que "as precondições para uma joint venture são as que as empresas têm que criar institutos para o desenvolvimento tecnológico, e os produtos têm de ser introduzidos no mesmo nível que aquele encontrado nos países desenvolvidos na década de 1990" (CASSIOLATO; PODCAMENI, 2015). Assim, as indústrias chinesas, exigiam das multinacionais o licenciamento da tecnologia como uma precondição para seu investimento no país. Apesar disso, as novas tecnologias também chegavam por meio de subsidiárias e importação de hardware seguida de engenharia reversa (LIU; WHITE, 2001).

O caso dos equipamentos para energia elétrica ilustra bem o desempenho desse formato de políticas. Em 1996, para a construção da represa das Três Gargantas (atual maior usina hidrelétrica do mundo) o governo exigiu, explicitamente na licitação para o projeto, a inclusão de empresas estrangeiras e domésticas. Para a margem esquerda da represa, os vencedores de doze dos catorze contratos de equipamentos poderiam ser empresas estrangeiras, mas as chinesas deveriam necessariamente participar dos consórcios, sendo que uma tinha de ser a principal proponente nos últimos dois contratos. Em todos os casos, as empresas estrangeiras tinham de realizar, em conjunto com os parceiros chineses, o design e a produção do equipamento que seria instalado. Este tipo de regime especial apoiou o início do aprendizado da Harbin Electricity Power Station 
Equipment (empresa chinesa), um dos principais atores globais nesta área atualmente (YU, 2007).

As empresas estrangeiras ainda eram obrigadas a vender seus produtos majoritariamente para o mercado internacional. Assim, as empresas domésticas seriam protegidas da competição externa e receberiam mais investimentos privados, pois a principal rota para empresas estrangeiras investirem na China se tornaria a participação acionária em empresas domésticas. Tal rota se originou com a política de privatizações parciais ou completas das empresas estatais (gaizhi), que visava a redução dos custos governamentais, o aumento da produtividade e lucratividade e a criação de oportunidades para empresas privadas participarem e se expandirem. Essas reformas reduziram a intervenção governamental nas operações, gerando mais autonomia e delegando a administração do governo central para os gerentes de cada empresa.

Ao mesmo tempo em que o governo incentivava a entrada de empresas estrangeiras por meio da retirada de barreiras de entrada e encorajava a criação de empresas não-estatais (principalmente locais), às estatais foi permitido que mantivessem parte dos lucros totais da produção, além de um maior poder de decisão sobre planos de produção, ajustes de mão de obra e marketing de produtos. Em 1984, os direitos dessas empresas foram ampliados, abrangendo também o planejamento de produção, a compra de insumos, o pagamento e recrutamento de trabalhadores e o uso do lucro mantido (SONG, 2018). Todo esse processo de flexibilização gerencial, que evidentemente ampliou as capacidades gerenciais, sempre complementares às tecnológicas (BELL; FIGUEIREDO, 2012), foi concomitante a uma descentralização do poder estatal para o nível local (províncias e cidades), que passou a ter mais liberdade para decidir sobre o uso de seus fundos, principalmente com o suporte às empresas locais financeiramente e com taxações específicas. A partir de meados dos anos 2000, os governos locais passaram a encorajar as empresas a investirem pesado em projetos voltados para o desenvolvimento da economia regional (MATTLIN, 2007).

Em busca de pontos de melhoria, em 1985, o então primeiro-ministro Zhao Ziyang entendeu que uma das grandes desvantagens do sistema chinês era a desconexão entre a C\&T e a produção. Herança da organização soviética, os institutos de pesquisa sustentavam departamentos relevantes, numa relação vertical, sem canais de interação com a sociedade ou diretas com o setor produtivo. Por isso, a divisão do trabalho passou 
a ser menos rígida ${ }^{2}$, com atividades não mais definidas exclusivamente por fronteiras organizacionais. Houve por exemplo, a agregação das atividades de P\&D nas rotinas das organizações manufatureiras e a participação da academia em atividades de implementação (LIU; WHITE, 2001). Em termos práticos, o número de departamentos de P\&D internos às empresas cresceu de 7.000 em 1987 para 24.000 em 1998 (CHINA SCIENCE AND TECHNOLOGY STATISTICS, 1992, 1998). Além disso, 242 institutos ligados à Comissão de Economia e Comércio foram fundidos junto às empresas, tornando-se unidades internas de $\mathrm{P} \& \mathrm{D}$, ou convertendo-se em empresas tecnológicas

Ainda ocorreram diversos processos de fusão e a abolição de centenas de institutos públicos de pesquisa, além da conversão de alguns em empresas privadas (JACKOBSON, 2007), em decorrência da reorganização das finanças estatais.

As Conferências Nacionais de C\&T em 1978, 1985, 1995 e 1999, ainda foram importantes para o debate sobre a criação de regimentos legais que estimulassem a entrada de empresas estrangeiras no país e fomentassem a inovação doméstica. Segundo Cassiolato e Podcameni (2015, p. 502), “os desenvolvimentos tecnológicos eram considerados como commodities no sistema legal da época, e as mudanças no marco legal visavam estabelecer mecanismos por meio dos quais a transferência de tecnologia deveria ser compensada de acordo com seu valor". Dessa forma, para criar um ambiente favorável para a inovação e para que as empresas se sentissem seguras no desenvolvimento de suas inovações, um conjunto de leis foi paulatinamente sendo adotado, algumas delas estão no Quadro 1.

A Lei de Patentes chinesa se baseou no conceito alemão de gebrauchmuster (modelo de utilidade), que não exige que o solicitante da patente explique como desenvolveu o produto. Ele segue, também, o modelo europeu (primeiro a depositar) e não o americano (primeiro a inventar). A combinação destes dois fatores foi consciente e tem dado vantagens evidentes às empresas locais em comparação às estrangeiras, que podem se utilizar da engenharia reversa e de um posterior patenteamento mais rápido do que o do produto "original". De forma geral, as leis moldaram o ambiente organizacional, atraindo empresas internacionais que obtiveram mais garantias para iniciar suas operações e apoio para que as empresas locais não fossem suprimidas pelos novos atores.

\footnotetext{
2 Destacam-se as seguintes políticas: Regulação Temporária da Expansão da Autonomia dos Institutos de Pesquisa de 1986; Opiniões acerca da Continuidade da Reforma do Sistema de C\&T de 1987; e, Decisões sobre Diversos Aspectos do Aprofundamento da Reforma do Sistema de C\&T de 1988.
} 
Já na década de 1990 a estratégia de C\&T, envolveu o estímulo a professores para a criação de empresas privadas voltadas para o desenvolvimento, a transferência, a consultoria e aos serviços de tecnologia. Essa transformação na visão do papel das universidades permitiu que elas se tornassem proprietárias e principais acionistas de suas próprias empresas produtivas e aumentou os recursos a elas disponíveis. Um exemplo é o lançamento do programa TORCH, criado para incentivar o surgimento de novas empresas de tecnologia a partir das universidades e institutos de $\mathrm{P} \& \mathrm{D}$ existentes.

Quadro 1 - Principais marcos legais da transformação do SNI da China, 1978 a 2002.

\begin{tabular}{|l|l|}
\hline Trademark Law & 1982 \\
\hline Lei de Patentes & 1985 (com emendas em 1992 e 2010) \\
\hline Lei do Contrato de Tecnologia & 1987 \\
\hline Copyright Law & 1990 \\
\hline Lei Antitruste & 1993 \\
\hline Lei do Progresso da Ciência e Tecnologia & 1993 \\
\hline Adoção do Tratado de Cooperação de Patentes & 1994 \\
\hline Lei da Garantia & 1995 \\
\hline Lei de Instrumentos Negociáveis & 1996 \\
\hline Lei de Seguros & 2002 \\
\hline Lei de Promoção de Pequenas e Médias Empresas & 2002 \\
\hline
\end{tabular}

Fonte: CASSIOLATO; PODCAMENI (2015); LIU;WHITE (2001). Elaboração pelos autores.

Segundo Hayan e Yuan (2011), a missão das universidades se voltou para o desenvolvimento econômico e para o avanço do setor de Ciência e Tecnologia e, portanto, uma das principais características do SNI chinês pós 95 foi a maior interação entre empresas, universidades e instituições de pesquisa. Somado a isto, as instituições de educação superior passaram por transformações estruturais seguindo os modelos americano e europeu. As universidades, que na década de 50 haviam sido separadas, se fundiram tornando-se muito maiores. Como é o caso da Zhejiang University, junção da Hangzhou University, Zhejiang Agriculture University, e Zhejiang Medical University.

Mas as fusões não diminuiram o número de instituições. Em 1978 eram 598 e em 20172.631 (CHINA STATISTICS YEARBOOK, 2009, 2018), um aumento de 339\% como resultado de uma política de abertura de universidades no interior do território, em busca de uma maior coesão nacional. O número de graduados cresceu exponencialmente, 
passando de 16,5 mil pessoas em 1978 para mais de 735 mil em 2017, um crescimento de 4359\% (CHINA STATISTICS YEARBOOK, 2009, 2018).

Ainda que as reformas estivessem aumentando o caráter liberal da economia chinesa, seria exagero afirmar que se aproximava de qualquer ideal nesse sentido, uma vez que, por exemplo, os setores estratégicos da economia deveriam ser dominados por empresas de propriedade estatal. De fato, a maioria dessas empresas são originárias da antiga economia comunista e faziam parte do processo de desenvolvimento orientado para indústrias pesadas, iniciado em 1950. Depois das reformas, no entanto, elas estão cada vez mais orientadas para o mercado e rapidamente se internacionalizando, com listas públicas em bolsas de valores no exterior. Todavia, elas ainda são estatais e fazem parte de grupos empresariais maiores com empresas-mãe no centro de suas operações (BRØDSGAARD, 2012).

Nos outros setores ainda há a influência estatal por meio de compras ou listas prescritas de compra, como no caso da lista de reembolso da indústria farmacêutica. Neste caso, a China é o segundo maior mercado farmacêutico do mundo e utiliza-se disto para conseguir negociar a diminuição dos preços dos medicamentos em troca da inserção destes na lista de reembolso do Sistema Nacional de Seguro Médico. Com isso, para a nova lista (com efeito a partir do início de 2020), o país conseguiu adicionar 70 novos medicamentos (incluindo 22 drogas contra o câncer) e uma média de diminuição de 60,7\% dos preços com as companhias farmacêuticas (CHINA DAILY, 2019).

Quanto aos setores estratégicos, em 1999, durante o $15^{\circ}$ Congresso Nacional, foram especificados quatro grupos de indústrias em que as estatais deveriam manter o domínio: alta tecnologia, recursos naturais não renováveis, utilidades públicas e serviços de infraestrutura, e segurança nacional (BROADMAN, 2002). Posteriormente, em 2006, o Conselho de Estado sugeriu uma lista mais específica de grupos de indústrias prioritárias, ilustrada pelo Quadro 2.

Quadro 2 - Grupos de indústrias prioritárias na China, a partir de 2006.

\begin{tabular}{|l|l|}
\hline Grupos de Indústrias & Indústrias incluídas \\
\hline Indústrias chaves e estratégicas & $\begin{array}{l}\text { Defesa, geração e distribuição de energia, óleo e petroquímica, } \\
\text { telecomunicações, carvão, aviação civil e náutica }\end{array}$ \\
\hline Indústrias básicas e fundamentais & $\begin{array}{l}\text { Bens de capital, automobilística, IT, construção, ferro, metais } \\
\text { básicos, química, agrimensura e P\&D }\end{array}$ \\
\hline
\end{tabular}


Fonte: SONG (2018). Elaborado pelos autores.

Negócios financeiros, investimentos, medicina, materiais de construção e exploração geológica

Apesar dos balanços internacionais e de algumas dificuldades, a China continuou seu processo de modernização e no final dos anos 90 inseriu novas transformações. No tocante à qualificação da mão de obra, os graduados em universidades passaram a ter mais liberdade em escolher onde iriam trabalhar após a formação (apesar de algumas restrições relativas a residência). O que gerou um fluxo de cientistas e técnicos de empresas estatais para empresas privadas, que ofereciam melhores condições de trabalho e remuneração. Além do processo de "internal brain drain", quando muitos técnicos foram atraídos para áreas não diretamente ligadas à inovação, como o trabalho em bancos de investimento e finanças (LIU;WHITE, 2001).

A despeito dos cortes já mencionados em algumas organizações, o governo aumentou o financiamento direto da pesquisa básica. Em 1998, com o lançamento do Programa 973, disponibilizou 5 bilhões de RMB para o suporte de pesquisa básica. Além de 5,4 bilhões de RMB alocados para a Academia Chinesa de Ciências, voltados para o desenvolvimento de tecnologias de nível internacional em ciências básicas e infraestrutura técnica ${ }^{3}$ (FANG, 2000).

Podemos observar o primeiro período, entre 1978 e 1984, como uma fase de reconstrução do aparato de Ciência e Tecnologia chinês, com a revitalização de institutos de pesquisa, laboratórios e centros tecnológicos.

\begin{abstract}
Neste período, o fortalecimento das capacitações científicas e tecnológicas se tornou prioridade nacional. Além de focar na geração de novos programas de C\&T, o país foi progressivamente alinhando políticas tarifárias, financeiras e fiscais, reforçando uma visão sistemática de inovação. (CASSIOLATO; PODCAMENI, 2015, p. 497).
\end{abstract}

Também nesse período, o governo começou a estimular o catching up tecnológico por meio da aquisição, absorção e imitação de tecnologias, mediante as Regulamentações para o Encorajamento de Contratos de Importação de Tecnologia (1985) e as Regulamentações para o Trabalho de Absorção e Assimilação de Tecnologias (1986).

\footnotetext{
${ }^{3}$ Especialmente em indústrias estratégicas, como tecnologia da informação e biotecnologia.
} 
Em suma, o governo central passou a ter uma visão sistêmica da inovação e consolidou as bases do ambiente inovador por meio da inserção de diversas políticas fiscais, tarifárias, financeiras e de inovação, além da atualização do regimento interno direcionado à atração de tecnologias estrangeiras. O capital estrangeiro entrou no país como uma estratégia do governo para conseguir aumentar o desempenho das empresas domésticas. Assim, vale destacar o ativismo estatal na busca por padrões internacionais de instituições que permitissem a inovação organizacional das empresas chinesas e o reconhecimento que grandes transformações como as desejadas demandariam tempo de aprendizado, típicos de um planejamento de longo prazo (mesmo que esse seja dividido em diversos planos de curto-médio prazo).

\section{Mutações da esfera produtiva e científica em prol da capacitação tecnológica autóctone (endógena) - 2000-2018}

Apesar dos diversos esforços do governo para o avanço da C\&T, no início do século XXI o SNI chinês ainda mantinha deficiências significativas, como as fracas interações entre empresas e infraestrutura de C\&T e a capacidade empresarial limitada aos níveis intermediários. Os chineses eram capazes de absorver e adaptar em velocidade, mas sem força suficiente para escapar da armadilha da renda média, que sofrem os países incapazes de aumentar o valor agregado em seus produtos de exportação depois de terem explorado vantagens de excesso de mão de obra.

Tal dificuldade fora percebida já em 1995, quando definiu-se claramente a busca da centralidade da C,T\&I no processo de desenvolvimento da China. Quase todas as políticas se centraram na reestruturação das instituições de investigação científica e na melhoria da capacidade de inovação das empresas. Portanto, as atividades de P\&D começaram a ter um maior peso no SNI chinês, o que revelou resutados positivos como nota-se no Gráfico 1, que revela um aumento do gasto de P\&D/PIB na China de $1 \%$ para $2,13 \%$ entre 2000 e 2017, enquanto que os gastos absolutos cresceram mais de $2.000 \%$. 
Gráfico 1 - Dispêndios com P\&D e porcentagem do PIB em P\&D da China, 20002017.

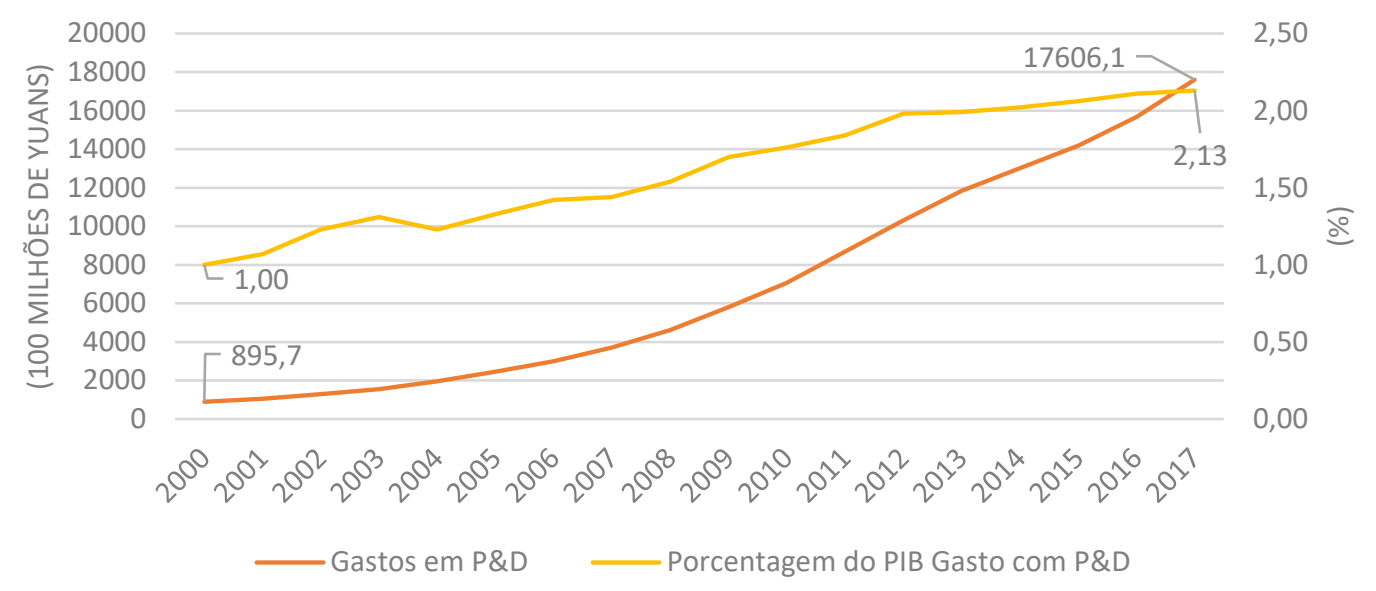

Fonte: CHINA STATISTICS YEARBOOK, 2009, 2010, 2012, 2013, 2015, 2018. Elaborado pelos autores.

\subsection{Aspectos recentes da mutação das empresas chinesas}

A partir de 2003, as empresas estatais foram direcionadas à internacionalização, o que incluiu abertura de capital em bolsas de valores domésticas e internacionais, inclusive via fusões e aquisições (F\&A) internacionais, o que custumava estar relacionado ao acessos seguros a matérias-primas críticas, incluindo energia (SONG et al. 2011). Como reflexo, em 2014, 98 empresas chinesas figuravam na lista Fortune Global 500, em setores como energia, finanças, telecomunicações, engenharia e construção e automobilística. (JEFFERSON, 2016). O processo se aprofundou na segunda década dos anos 2000, que incluiu nova rodada de flexibilização a participação de empresas estrangeiras em indústrias estratégicas e ampliação da permissão para que o capital das empresas estatais passasse a ser investido em projetos de empresas privadas, com foco em high tech e new industries.

Essa diretriz de viés liberalizante enganaria o leitor desavisado, pois os principais administradores de estatais ainda são indicados e aprovados pelo conselho do Partido Comunista Chinês. A chinesa Unicom, operadora de telecomunicações, por exemplo, tem quatro investidores como membros de seu conselho administrativo, que devem trazer experiências do setor privado para a melhora da eficiência da empresa, entretanto, o Partido ainda sobrepõe o poder desses por meio de seus indicados.

Tal integração particular não vem se desenvolvendo sem problemas. A interferência governamental nas operações empresariais vem sendo acompanhada de 
denúncias de corrupção, as quais, são um dos principais locus de atuação das novas reformas. Para Leutert (2016), esse é um dos maiores desafios contemporâneos, sobretudo porque a rede de relações dos denunciados costuma ser ampla e com fortes ligações com membros influentes do Partido.

Outra particularidade relevante à compreensão do processo de mutação do SNI chinês reside na reforma sobre a maneira de analisar o desempenho das empresas estatais. Antes de retratar as mais recentes é preciso ter em conta que este tipo de empresa, desde sua origem, carrega consigo uma importância social elevada e distinta da tradicionalmente concebida por modelos mentais ocidentais. Não por outra razão, por muito tempo, foram retratadas como sob o adjetivo de "ineficientes". Além de lucro e market share, planos estatais, imprimiam a elas responsabilidades de bem-estar social. Bai, Lu e Tao (2006), atribuíram a baixa performance econômica de muitas empresas à essa natureza "multi-objetiva" de suas operações.

As atividades incluíam gastos com saúde, moradia e educação a seus trabalhadores, além de objetivos macroeconômicos como a manutenção da estabilidade social por meio do fornecimento de emprego e pela proteção do trabalhador, especialmente quando a segurança social local é subdesenvolvida ou durante choques econômicos, quando empresas privadas naturalmente se protegeriam diminuindo empregos. Nota-se que a visão estratégica ao bem estar público acompanhou o avanço dessas empresas, o que, não obstante, sempre foi parcialmente compensado por acessos privilegiados a recursos controlados pelo governo (terras, por exemplo), e a empréstimos e linhas de crédito especiais.

A característica particular da firma estatal chinesa demanda formas também particulares de análise de seu desempenho. Desde 2015, os critérios de desempenho foram subdivididos para duas categorias de empresas, as públicas e as comerciais. A performance das públicas passou a responder a critérios de: capacidade de controle de custos, qualidade de seus produtos e serviços, e estabilidade e eficiência de suas operações. Enquanto o aumento da competitividade de mercado e aperfeiçoamento da performance financeira, são critérios às empresas comerciais.

Além disso, por meio de fusões, foram criadas as "campeões nacionais" como uma forma de eliminar empresas não lucrativas, sem sacrificar empregos e ampliar escala e potencial competitividade internacional, além de acabar com guerras comerciais internas, que traziam prejuízos a algumas delas. Em 2011, por exemplo, as empresas CSR e CNR travaram uma guerra comercial por um contrato de uma ferrovia turca, que acabou 
ficando com uma empresa coreana. E ainda, em 2013, quando as duas novamente disputavam contratos de ferrovias para trens-bala na Argentina, a CSR propôs valores muito abaixo da CNR e ainda abaixo dos custos de produção. O que fez com que a Argentina passasse a desconfiar da qualidade das empresas chinesas (FINANCIAL TIMES, 2014). A fusão das duas resultou em aumento da competitividade do setor de trens de alta velocidade chinês.

Outra particularidade residiu nas conexões entre a inovação para o mercado e o setor militar nos anos 2000, quando para fortalecer os complexos de defesa por meio das capacitações existentes na economia civil, o governo passou a estimular o aproveitamento de spin-offs entre as economias civil-militar. Com o intuito de criar uma autoridade que facilitasse a interação e o avanço coordenado criou-se o Ministério da Ciência, Tecnologia e da Informatização, resultado da integração entre o Ministério da Ciência, Tecnologia e Indústria para Defesa, o Ministério da Informação e o Ministério da Reforma.

Alguns exemplos icônicos dessa integração são a Huawey e a ZTE, gigantes no setor de telecomunicações com amplas ligações com o complexo militar, a última sendo fundada inclusive por um grupo de empresas estatais do Ministério da Indústria da Aviação da China em 1985. Outros grandes exemplos são a Haier, maior vendedora de bens de linha branca do mundo e a Hafei, Asic e Chery, que em suas estratégias tecnológicas não tentaram inicialmente concorrer com as líderes tecnológicas globais (via inovações radicais), mas sim em engenharia reversa e licenciamento, posteriormente, desenvolvendo tecnologia e inovação para o mercado local e apenas depois ingressando no mercado global.

Do que foi explorado até aqui, notou-se que não apenas a mutação das firmas estatais envolveu maior abertura a participação de agentes privados estrangeiros, com objetivo de ganhar competências não internalizadas por chineses; mas também que, as empresas estatais passaram a ter maior liberdade para participar do capital de outras empresas estrangeiras, o que envolveu elevação do balanço patrimonial em favor da China; houve mudança nas formas de avaliação das empresas estatais, sem que seu papel estratégico social deixasse de existir; as estatais passaram por um processo intencional de fusões de forma a ampliar suas escalas produtivas e acelerar um processo de internacionalização; assim como, setores estratégicos à soberania nacional, como o de defesa, tiveram mudança institucional estratégicamente concebida em torno da elevação da capacidade tecnológica. 
Esses são elementos centrais à compreensão das peculiaridades da resposta chinesa ao desafio de integra-se vitoriosamente à dinâmica global de produção e inovação contemporânea, sem que com isso houvesse perda da capacidade de gestão estratégica econômica e social da direção estatal.

Os dados abaixo apontam os novos direcionamentos como uma forma de dar passos largos para sair da situação de um sistema passivo, marcado pela absorção e adaptação de tecnologias, para outro que ativamente acompanha de perto a evolução das fronteiras tecnológicas, quando não as empurram. Isso também permite dizer que a visão estratégica, de longo prazo chinesa, esteve acentada na modéstia e sobre as próprias possibilidades ante à velocidade da mutação do capitalismo, o que estimulou a elaboração de uma forma particular de integração que amplia a participação estrangeira no presente, mas amplia a influência chinesa no futuro, à medida que forem sendo recolhidos os frutos de seu sucesso.

Tais frutos podem ser visualizados nos gráficos a seguir. O Gráfico 2, por exemplo, mostra que bons resultados podem ter gerado a intensificação das atividade mais nobres de inovação, as de pesquisa e desenvolvimento, ou seja, as que costumam demandar um nível mais elevado de elaboração criativa e que, por isso, costumam resultar em inovações. Nota-se que, além da extraordinária intensificação do volume de recursos total, o uso de recursos das empresas para a realização de $\mathrm{P} \& \mathrm{D}$, que representava $71 \%$ de cerca de Y\$ 1.800 bilhão, em 2004 passou a 79\% de cerca de Y\$ 15.000 bilhões, em 2016.

Gráfico 2 - Divisão da composição do dispêndio em P\&D por fonte da China, 20042016.

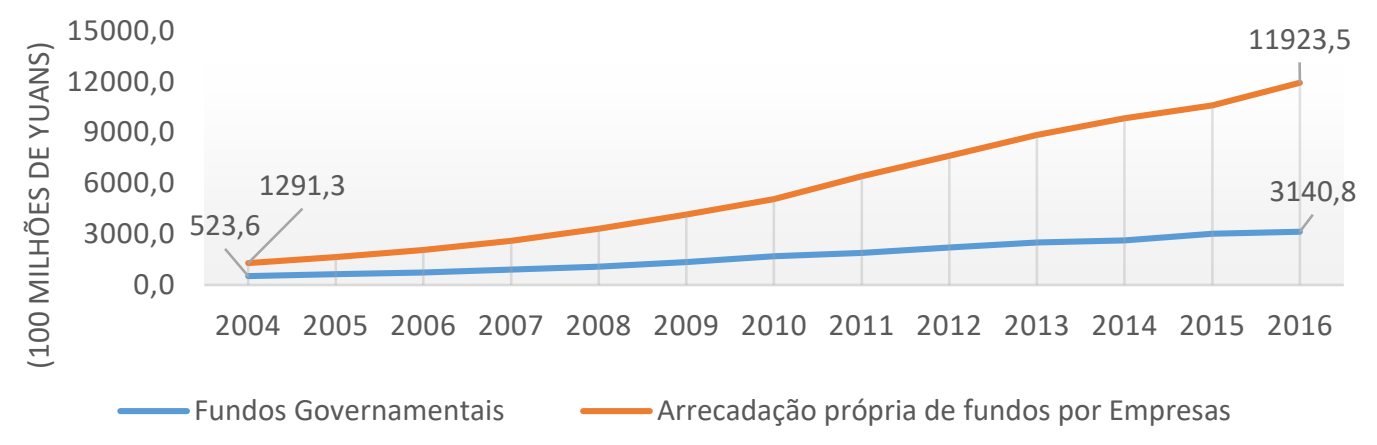

Fonte: CHINA STATISTICS YEARBOOK, 2009, 2010, 2012, 2013, 2015, 2018. Elaborado pelos autores.

O Gráfico 3 mostra que o desenvolvimento experimental tem se tornado o principal locus dos esforços de $\mathrm{P} \& \mathrm{D}$ chineses, os quais costumam ser realizados pelo 
setor privado, pela lógica de curto prazo que costuma guiar seus empreendimentos. Isso poderia ser lido como sinal de que os processos de inovação no SNI chinês continuam voltados às inovações incrementais, típicas dos projetos de curto prazo. Contudo, sabendo-se que é a complementaridade das diferentes formas de $\mathrm{P} \& \mathrm{D}$ que costuma explicar uma capacidade inovadora mais próxima da fronteira.

Gráfico 3 - Dispêndios em P\&D discriminados por destinação da China, 2000-2017.

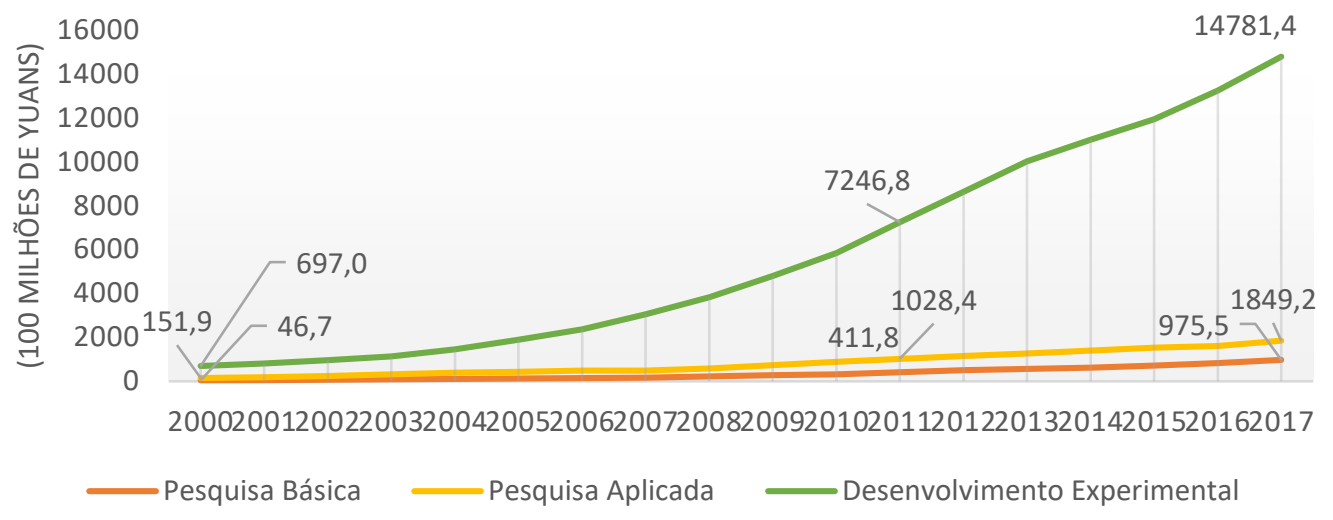

Fonte: CHINA STATISTICS YEARBOOK, 2009, 2010, 2012, 2013, 2015, 2018. Elaborado pelos autores.

Entende-se que o SNI chinês tem revelado potencial, uma vez que a pesquisa aplicada teve um incremento de cerca de $1.000 \%$ em 17 anos, enquanto que a pesquisa básica, normalmente financiada por recursos públicos, cujos objetivos são de mais longo prazo, teve um incremento de mais de $2.000 \%$ no período. Isso significa que tem crescido continuamente a potencial sinergia em torno de conhecimentos de diferentes naturezas (científica, tecnológica e produtiva) que costumam estar na raíz da elevada capacidade inovadora de um sistema.

Também, chama atenção o desempenho tecnológico revelado pelo número de patentes concedidas que cresceu $1.643 \%$ e pelo número de invenções patenteadas, que cresceu 3.212\%, entre 2000 e 2017, conforme o Gráfico 4. Também, se destaca o fato de que em termos percentuais, os pedidos de patentes feitos por residentes chineses aumentaram em relação aos pedidos feitos por não residentes, o que aponta capacidade endógena de geração de progresso técnico, bem diferente do que aconteceu nos países latino-americanos no período (BITTENCOURT; CHIARINI, 2019). 
Gráfico 4 - Número de patentes concedidas na China, 2000-2017.

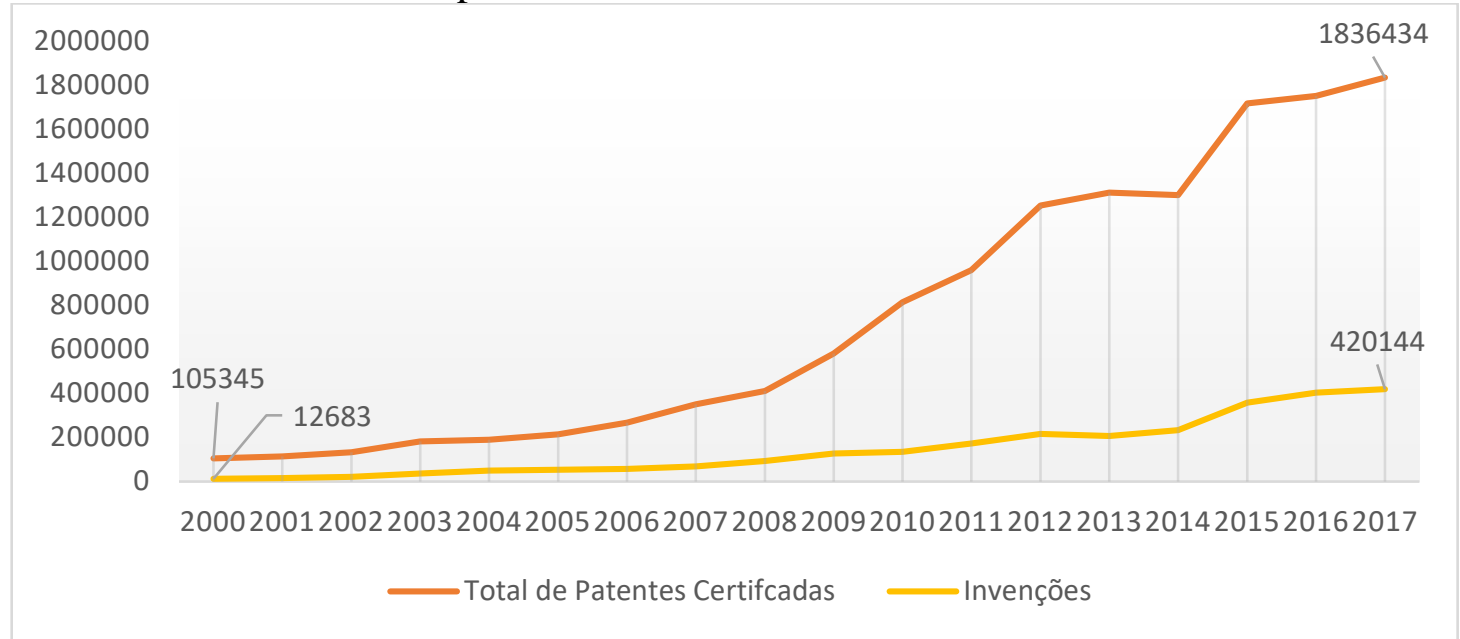

Fonte: CHINA STATISTICS YEARBOOK, 2009, 2010, 2012, 2013, 2015, 2018. Elaborado pelos autores.

Esse vigoroso desempenho tecnológico que foi acompanhado por avanços na capacidade de gestão financeira e educacional, muito superior a países latino-americanos (BITTENCOURT; MATOS; CHIARINI, 2019), esteve sustentado em diferentes motores de demanda agregada. Desde a década de 1980, as exportações aumentaram sua participação no PIB chinês, passando de menos de 10\% para mais de 30\% em 2006. Enquanto que os investimentos (maquinaria, construção civil não residencial e P\&D) elevaram-se de cerca de 30\% para aproximadamente 50\% nos 35 anos que se seguem a 1980. Já o consumo final (demanda das famílias) diminuiu seu peso relativo, ainda que nesse período mais de 850 milhões de chineses tenham saído da situação de pobreza extrema, fazendo com que o país passase de uma situação de cerca de $87 \%$ de população em situação de extrema pobreza para outra de 0,5\% entre 1981 e 2016 (WORLD BANK, 2019).

O Gráfico 5 mostra que as exportações foram responsáveis pelo impulso produtivo ao menos até a crise de 2007. Com a crise mundial de sub-prime, o motor foi substituído pelo consumo interindustrial, ou melhor, pelo investimento, revelando a elevada vantagem de produzir na China, depois de décadas de avanços produtivos e tecnológicos. 
Gráfico 5 - Forças de Expansão do PIB Chinês - Consumo, Governo, Investimentos e Exportações, \% PIB - 2004-2018.

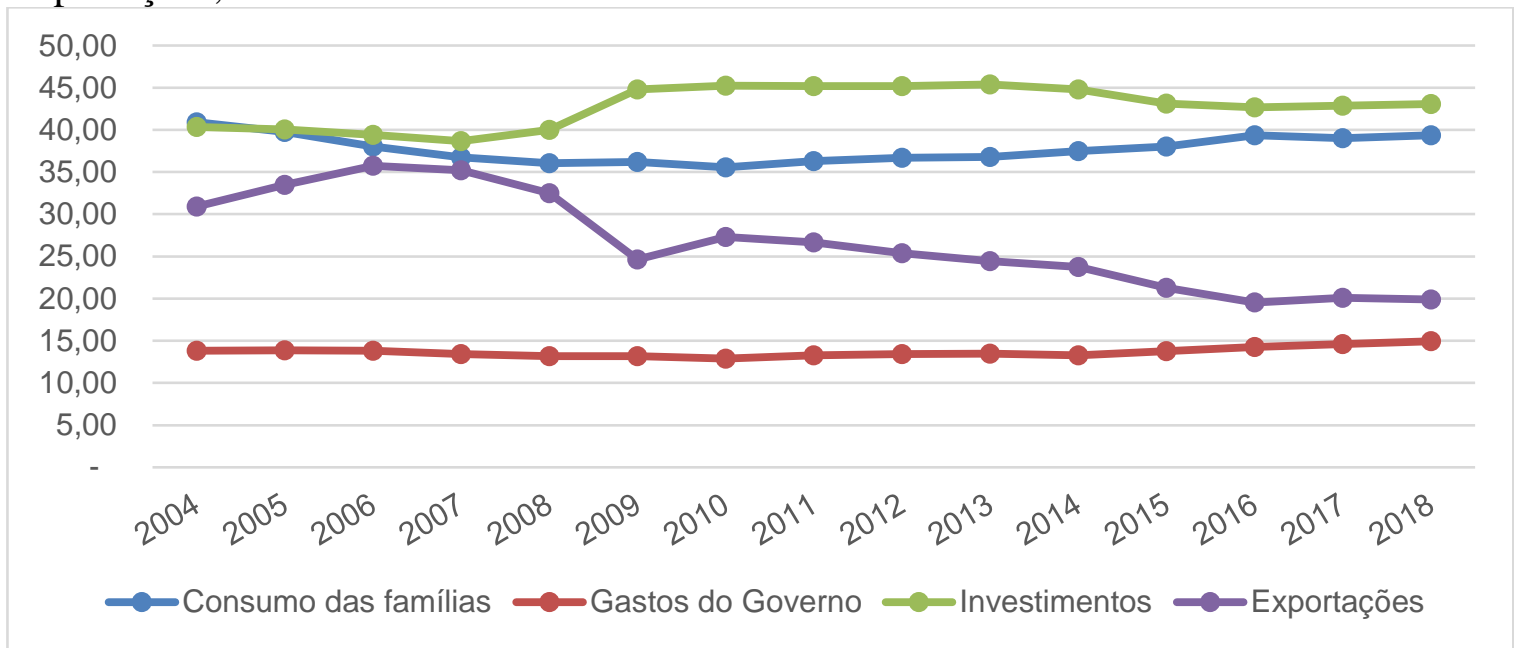

Fonte: Elaborado pelos autores, com base nos dados do FMI.

Tal interpretação encontra sustentação no movimento de transformação qualitativo da pauta de exportações, que inicialmente baseou-se em produtos de bens de consumo final (sobretudo têxteis e confecções) e foi sendo paulatinamente substituída por bens intensivos em capital e tecnologia, ao mesmo tempo em que a pauta de importação apresentou declínio da participação de bens de capital e elevação das commodities de consumo final.

Ainda que materiais eletrônicos, especialmente válvulas de cátodos, utilizadas para a produção de telas de computadores, telefones e televisores, continuem a representar uma parcela significativa das importações. Como mostraram Mathai, et.al. (2016) as transformações nas pautas de importação e exportação revelam que a dependência de importações diminuiu ao longo do tempo, o que sugere movimento virtuoso nas cadeias globais de valor, inclusive no pós-crise 2008, quando as exportações deixaram de representar o principal motor ao desenvolvimento chinês. Em verdade, não apenas bens intensivos em capital, mas também em trabalho e, sobretudo, em conhecimento tiveram suas taxas de valor agregado ampliadas no período, o que reforça a qualidade da inserção nas cadeias globais e revela um sentido de desenvolvimento totalmente alinhado à expectativa virtuosa schumpeterina. 


\subsection{Mutação e desempenho da universidades e centros tecnológicos}

Além de considerarem a formação social/política dos estudantes, as instituições chinesas de C\&T passaram a ter participação específica na estratégia de desenvolvimento econômico à longo prazo do país, tanto pela formação de mão de obra especializada, como pela participação direta na geração de renda e acúmulo de riqueza, seja via participação em empresas, aplicação de patentes ou mesmo com a geração de spin-offs (empresas privadas).

No tocante às spin-offs, Gu (1999), afirma que muitas escolhem utilizar as tecnologias desenvolvidas internamente para a própria produção, enquanto outras desenvolvem novas tecnologias e as licenciam ou vendem para outras empresas. Isso acontece de três formas, por meio do desmembramento de partes da organização para a criação de uma empresa totalmente nova, transformando institutos ou departamentos internos (que se mantém integrados como parte da organização) ou apoiando indivíduos que tenham formalmente deixado as organizações para criar uma nova iniciativa.

A existência das spin-offs, o aumento dos gastos com P\&D nas universidades e o consequente maior número de patentes (com destaque para as invenções) rementem à estratégia de passagem de uma capacidade imitativa e de geração de inovações incrementais para outra mais sólida, baseada na definição de novas trajetórias tecnológicas e em áreas de conhecimento do atual paradigma, nas quais manter-se competitivo demanda capacidade tecnológica e, assim agressividade tecnológica. Essas organizações estão destacando no mercado internacional, caso da Lenovo, produtora de computadores, que possui centros internacionais nos Estados Unidos e Japão, e que ainda mantém 29,10\% de seu capital acionário nas mãos da Legend Holdings Corporation Ltda. (Academia Chinesa de Ciências) (LENOVO, 2019). Assim, o discurso de Deng Xiao Ping em 1978 foi seguido e a educação continua como um dos pilares do desenvolvimento.

General education is basic to the training of scientific and technical personnel. We must carry out the Party's policy on education comprehensively and correctly, put it on the right track and introduce appropriate reforms, so as to ensure both quantitative and qualitative progress. Education is not just the concern of the educational units. (XIAOPING, 1978 apud CHINA, 2019, p. 6).

Além disso, em janeiro de 2006, foi produzido o Plano Estratégico Nacional de Médio e Longo Prazo para o Desenvolvimento da Ciência e Tecnologia (Penct) 2006- 
2020, que enfatizava a busca por inovações autóctones (indigenous innovations) e o mercado local como motor principal para a construção de um país orientado para a inovação endógena. As capacitações científicas e tecnológicas deveriam, portanto, ser voltadas para a superação dos problemas específicos da sociedade chinesa.

Com o plano, a importância das universidades novamente foi destacada e a busca por inovações autóctones gerou uma expansão dos recursos disponibilizados para o P\&D pelas universidades, tanto públicos quanto privados. Apesar da predominância do capital público no investimento em atividades de P\&D das instituições de ensino superior da China, a arrecadação própria de fundos por empresas teve uma expansão de $383,8 \%$, como mostra o Gráfico 6. Sendo essa arrecadação tanto por empresas de universidades, como de parcerias entre universidades e outras empresas.

Gráfico 6 - Fontes dos dispêndios em P\&D em instituições de ensino superior na China, 2004 a 2017.

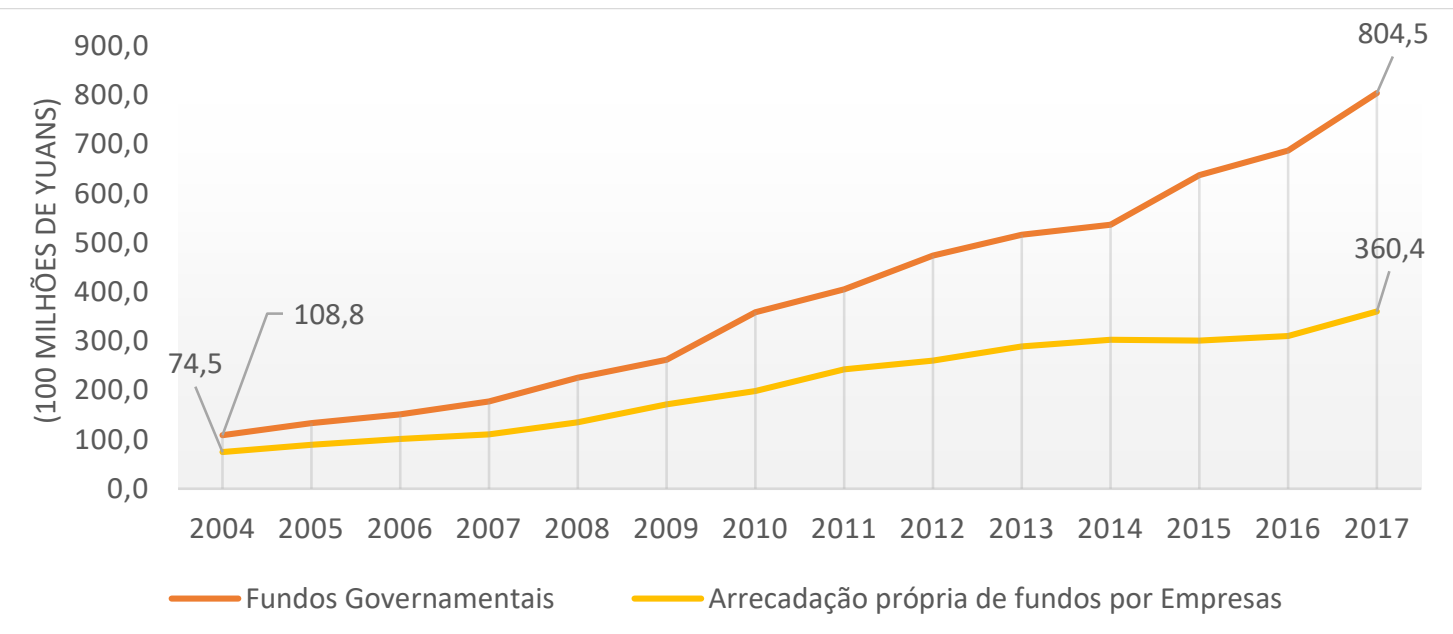

Fonte: CHINA STATISTICS YEARBOOK, 2009, 2010, 2012, 2013, 2015, 2018. Elaborado pelos autores.

Quanto ao destino desses montantes, notável a crescente do valor em pesquisa aplicada, o que aponta a integração com o ambiente produtivo, uma vez que esse tipo de esforço costuma estar associado à oferta de soluções para produtos e processos industriais já existentes. Não obstante, todas as formas de P\&D cresceram significativamente, como mostra o Gráfico 7.

A formação de quadros especializados também teve crescimento vertiginoso. De 2004 a 2017 o número total de pós-graduados cresceu em 1650\%. O aumento de doutores e mestres está exposto no Gráfico 8. 
Gráfico 7 - Dispêndios com P\&D em instituições de ensino superior na China de 2000 a 2017.

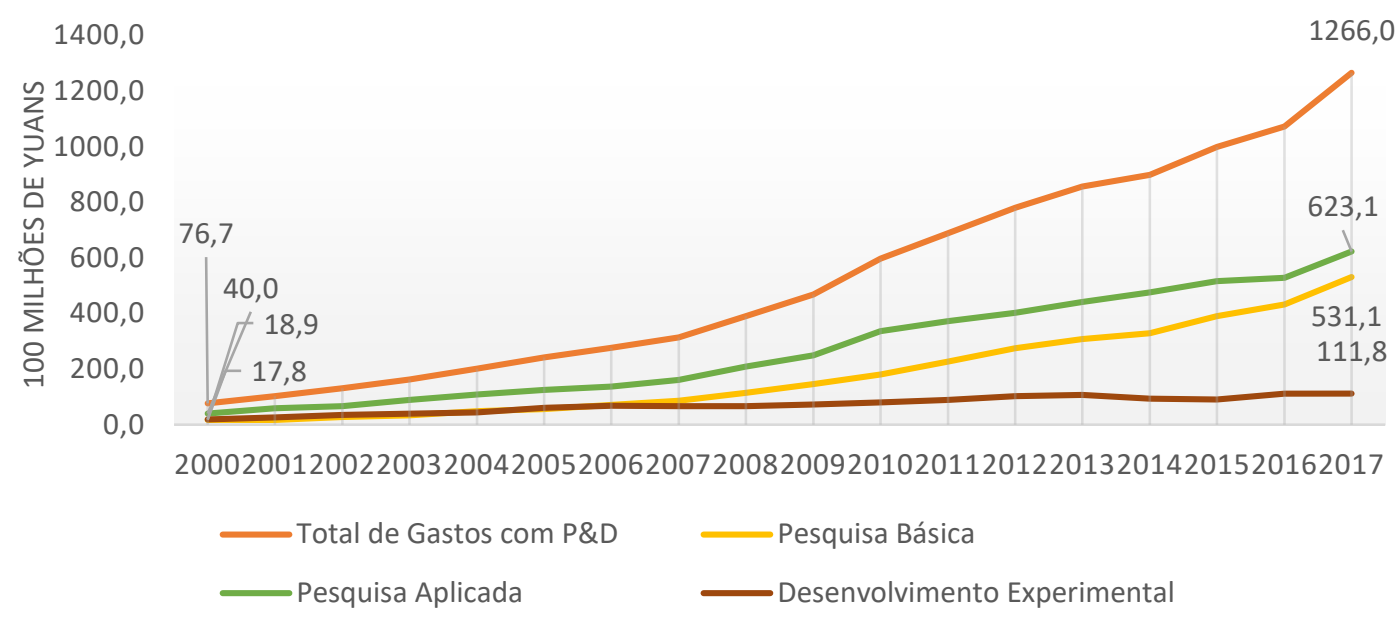

Fonte: CHINA STATISTICS YEARBOOK, 2009, 2010, 2012, 2013, 2015, 2018. Elaborado pelos autores.

Gráfico 8 - Número de alunos titulados em mestrados e doutorados na China de 2004 a 2017.

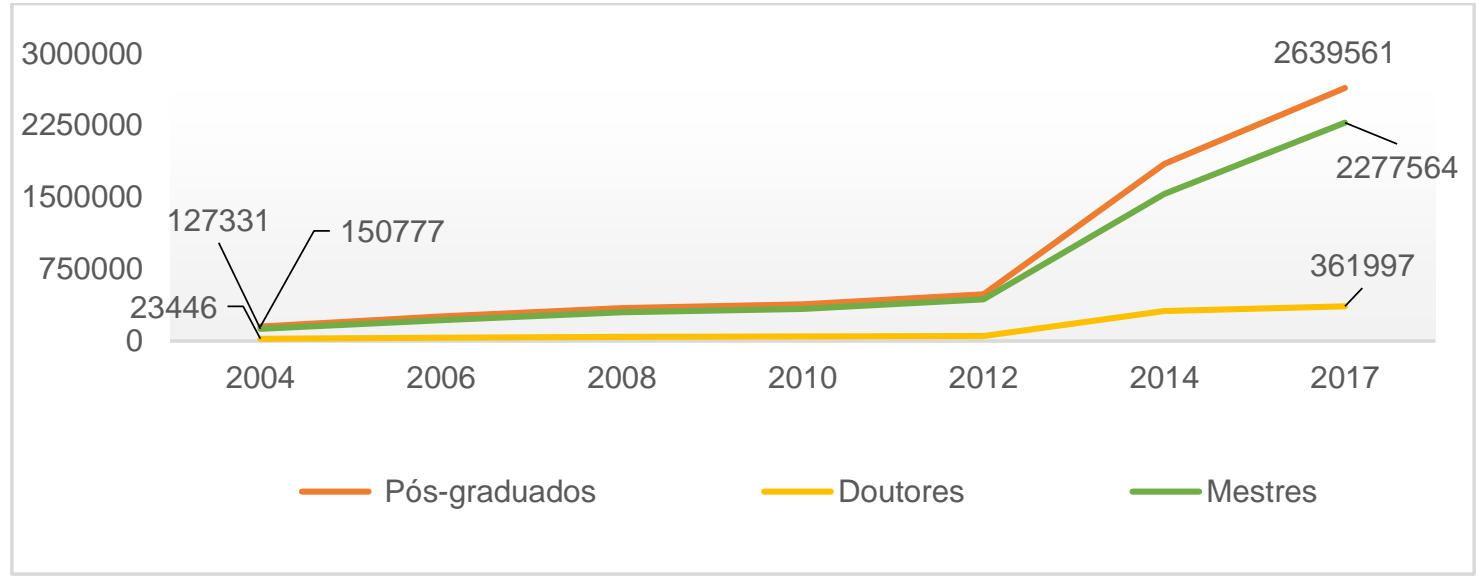

Fonte: CHINA STATISTICS YEARBOOK, 2009, 2010, 2012, 2013, 2015, 2018. Elaborado pelos autores.

Gráfico 9 - Patentes certificadas por universidades na China de 2004 a 2017.

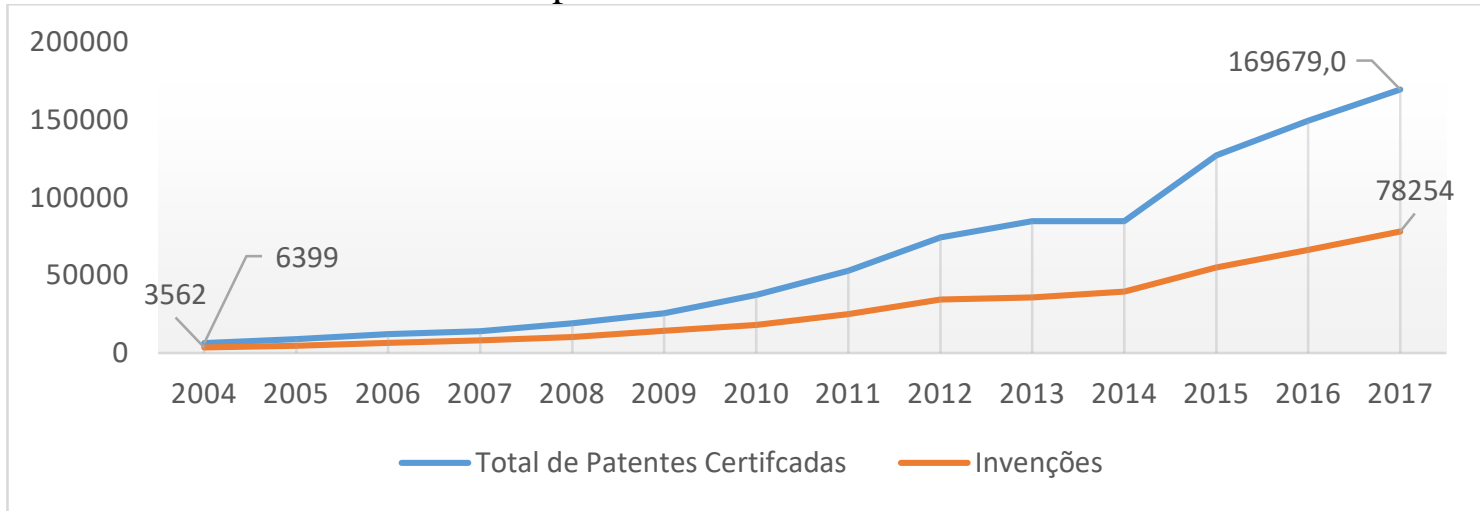

Fonte: CHINA STATISTICS YEARBOOK, 2009, 2010, 2012, 2013, 2015, 2018. Elaborado pelos autores. 
O número de patentes certificadas por universidades, que cresceu de 6.399 para 169.679 entre 2004 e 2017, representando um aumento de $2.551 \%$. Outro dado importante é o número de invenções patenteadas por universidades no período, que cresceu $2096 \%$, como mostra o Gráfico 9.

As reformas iniciadas em 1978 foram planejadas para criar maior capacidade inovativa no Sistema de Inovação chinês por meio da renovação das empresas e do aperfeiçoamento das universidades e centros de pesquisa; e o crescimento econômico consistente seria a consequência esperada pela interação entre esses atores renovados e o meio internacional. Como os dados apresentados indicam, houve de fato o aumento da capacidade inovativa do país e os resultados econômicos do país, nos últimos anos, deixam evidente que a relação de causa e consequência esperada por Deng Xiaoping ocorreu. Os frutos do planejamento a longo prazo e dos investimentos direcionados começaram a ser colhidos pela China.

\section{Conclusão: particularidade e adaptação - características históricas da virtuosidade do SNI chinês}

Desde a Revolução Comunista de 1949, a indústria chinesa passa por constantes reformulações, primeiramente para uma estrutura com bases soviéticas e com o poder centralizado no Estado. Entretanto, é a partir do discurso de Deng Xiaoping em 1978 que se percebe uma mudança na mentalidade do governo chinês, que admite a necessidade da renovação do país e inicia diversas reformas em busca de um Sistema Nacional de Inovação eficiente. As reformas aconteceram tanto no âmbito institucional, com a criação, por meio de leis e incentivos, de um ambiente favorável à inovação, quanto no âmbito organizacional, com a reformulação das empresas, universidades e institutos de pesquisa.

As reformas institucionais atraíram diversas empresas internacionais que antes não poderiam adentrar no país ou até mesmo não desejavam por não confiarem no ambiente empresarial chinês. A criação de legislações, que abrangem leis de patentes e de propriedade intelectual, somada à grande força de trabalho barata e as reformas organizacionais das entidades do país, garantiram a entrada e a permanência do capital estrangeiro na China. Essas últimas aconteceram de duas formas. Primeira, as reformas organizacionais no sentido de renovação dos equipamentos e tecnologias utilizados na China foram atualizados por meio do licenciamento de tecnologias estrangeiras, joint ventures, instalação de institutos de pesquisa e subsidiárias internacionais e a importação 
de hardwares seguidos de engenharia reversa. Segunda, houveram reformas organizacionais estruturais em que se destacam o incentivo ao empreendimento privado local, a abertura do capital das empresas chinesas ao mercado internacional e a entrada de administradores estrangeiros nos conselhos de grandes empresas.

O complexo educacional também foi reformado, agora com universidades voltadas à inovação autóctone e com iniciativas empresariais com bons resultados inovativos e financeiros. Assim, a enorme quantidade de capital investida durante todo o período estudado, os discursos oficiais do governo e os resultados empíricos demonstram que a China está comprometida com a estratégia de passagem de um país com alta capacidade imitativa e de geração de inovações incrementais para outro mais sólida, com base na definição de novas trajetórias tecnológicas e em áreas de conhecimento do atual paradigma. A China ainda deseja até 2049 se tornar a primeira potência mundial em desenvolvimento de tecnologia, quando comemorará o aniversário de 100 anos da proclamação da República Popular da China.

O caminho percorrido para a renovação do SNI chinês tem sido contínuo e intencionalmente dirigido por planos que reconhecem o papel central do domínio tecnológico como elemento central da superação da dependência externa, como o Made in China 2025. O artigo procurou mostrar que tal capacidade de reformulação é pilar fundamental dos extraordinários resultados, como o aumento do PIB de 2000 a 2018 em 1023\% (WORLD BANK, 2019).

Notável ademais que a mutação pouco caso fez de instituições da escola neoclássica de entendimento econômico. A Política Industrial e Tecnológica ativas chinesa nada assemelhansse às opções de outros países em desenvolvimento pela adesão ao Consenso de Washington na década de 1990 e 2000. Em clara contraposição, a atuação estatal chinesa moldou instituições em busca de soberania tecnológica e obteve como resultado a mais surpreendente evolução contemporânea de um Sistema Nacional de Inovações.

\section{Referências}

ANDREONI, A. Varieties of industrial policy. Stiglitz, J., Noman, A. Efficiency, Finance and Varieties of Industrial Policy, p. 245-305, 2016. 
ANDREONI, A.; CHANG, H-J. The political economy of industrial policy: Structural interdependencies, policy alignment and conflict management. Structural Change and Economic Dynamics, v. 48, p. 136-150, 2019.

BACHMAN, D. Bureaucracy, economy, and leadership in China: the institutional origins of the great leap foward. Cambridge University Press, Cambridge, p.262, 2006.

BAI, C.; LU, J.; TAO, Z. The multitask theory of state enterprise reform: empirical evidence from China. American Economic Review, ed. 1, v. 96, n. 2, p.353-357. American Economic Association. http://dx.doi.org/10.1257/000282806777212125, abril 2006.

BELL, M.; FIGUEIREDO, P. N. Innovation capability building and learning mechanisms in latecomer firms: recent empirical contributions and implications for research. Canadian Journal of Development Studies/Revue Canadienne D'études du Développement, v. 33, n. 1, p. 14-40, 2012.

BITTENCOURT, P. F.; BRITTO, J. N. P.; GIGLIO, R. Formas de aprendizagem e graus de inovação de produto no Brasil: uma análise exploratória dos padrões setoriais de aprendizagem. Nova Economia, v. 26, n. 1, p. 263-300, 2016.

BITTENCOURT, P. F.; CHIARINI, T.; Considerações finais: e a CHINA. In: CHIARINI, T.; CALIARI, T. (org.). Economia Política do Patenteamento na América Latina. ed.1, Jundiaí - SP: Paco Editorial, v. 1, p. 415-426, 2019.

BITTENCOURT, P. F.; MATOS, C. E.; CHIARINI, T. Comparing the performance of technological and social capabilities in Latin American and East Asian countries, 20002012. Perspectiva Econômica, v. 14, n. 2, p. 71-91, 2019.

BOEING, P.; SANDNER, P. The innovative performance of China's national innovation system. Frankfurt School - Working Paper Series, Frankfurt, p.1-41, 2011.

BROADMAN, H. G. A litmus test for China's accession to the WTO: reform of its stateowned enterprises. China and the Long March to Global Trade, Routledge, p. 63-114, 2002.

BRØDSGAARD, K. E. Politics and business group formation in China: the Party in control? The China Quarterly, Cambridge v. 211, p. 624-648, 2012.

CASSIOLATO, J. E.; PODCAMENI, M. G, B. As Políticas de ciência, tecnologia e inovação na China. In: CINTRA, M. A. M.; SILVA FILHO, E. B.; PINTO, E. C. (org.). China em transformação: dimensões econômicas e geopolíticas do desenvolvimento. Brasília: Ipea, p. 493-520, 2015.

CHINA, 2019. Speech at the opening ceremony of the National Conference on Science. China Through a Lens, 2019. Disponível em: <english.china.org.cn/english/features/dengxiaoping/103390.ht>. Acesso em: 28 de outubro de 2019. 
CHINA

DAILY.

Disponível

em:

https://www.chinadaily.com.cn/a/201911/29/WS5de0573aa310cf3e3557ac37.html>.

2019. Acesso em: 30 de janeiro de 2020.

CHINA STATISTICAL YEARBOOK. National Data, Beijing: National Bureau of Statistics of China. 2001, 2002, 2003, 2004, 2005, 2006, 2007, 2008, 2009, 2010, 2011, 2012, 2013, 2014, 2015, 2016, 2017, 2018. Disponível em: < http://data.stats.gov.cn/english/publish.htm?sort=1>. Acesso em: 15 de outubro de 2019.

COHEN, W. M.; LEVINTHAL, D. A. Absorptive capacity: a new perspective on learning and innovation. Administrative Science Quarterly, v.35, n.1, p.128-152, 1990.

EDQUIST, C.; HOMMEN, L. In: EDQUIST, C., HOMMEN, L. (org.), Small country innovation systems: globalisation, change and policy in Asia and Europe. Edward Elgar Publishers, (published in paperback 2009), 2008.

FANG, X. The role of government in science, technology and innovation: the case of China. Proceedings of the China-US Joint Conference on Technological Innovation Management, Beijing, 2000.

FREEMAN, Christopher. Catching up and innovation systems: implications for Eastern Europe. The knowledge-based economy in Central and Eastern Europe: countries and industries in a process of change. Basingstoke, Hampshir, Palgrave Macmillan, ISBN 1-4039-3657-9, p. 13-30, 2006.

FREEMAN, C.; SOETE, L. A economia da inovação industrial. Editora da UNICAMP, 2008.

FINANCIAL TIMES 2014. Disponível em: www.ftchinese.com/story/001059858. 2014. Acesso em: 10 de janeiro de 2020.

GU, S. China's industrial technology: market reform and organizational change. Routledge, Londres, p.440, 1999.

HAIYAN, W.; YUAN, Z. China: challenges for higher education in a high growth economy. In: GORANSSON, B.; BRUNDENIUS, C. (ed.). Universities in transition: the changing role and challenges for academic institutions. The Changing Role and Challenges for Academic Institutions, Ottawa: Springer, p. 143-170, 2011.

JAKOBSON, L. China aims high in science and technology. In: Innovation with chinese characteristics, New York: Palgrave Macmillan, p.1-36, 2007.

JEFFERSON, G. State-owned enterprise in China: Reform, performance, and prospects. Waltham: Brandeis University, Department of Economics and International Business School, 2016.

LENOVO. Disponível em: <https://investor.lenovo.com/en/ir/stockquote.php>. 2019. Acesso em: 22 de fevereiro de 2020. 
LIEBERTHAL, K. Governing China: from revolution through reform. Norton, New York, 1995.

LIST, F. Sistema nacional de economia política. ed. 3, São Paulo: Nova Cultural, p. 290, (Os economistas), ISBN 8513001538, 1989.

LIU, X.; WHITE, S. Comparing innovation systems: a framework and application to China's transitional context. Research Policy, [s. I.],_Elsevier BV, p.1091-1114, 2001.

LUNDVALL, B.A. National innovation systems - analytical concept and development. Tool, Industry and Innovation, v.14, n. 1, p.95-119, 2007.

MATHAI, K., GOTTLIEB, G., HONG, G. H., JUNG, S. E., Schmittmann, J. M., \& Yu, J. China's changing patterns of trade. In: China's changing trade and the implications for the $\boldsymbol{C L M V}$. International Monetary Fund, p.79, 2016.

MATTLIN, M. The Chinese government's new approach to ownership and financial control of strategic state-owned enterprises. Institute for Economies in Transition Bank of Finland, Helsinki, 2007.

MAZZUCATO, M. O estado empreendedor. Portfolio-Penguin, 2014.

MCDONALD, T. David. The technological transformation of China. National Defense University Press, Washington, p. 191, 1990.

PEREZ, C. Cambio técnico, restructuración competitiva y reforma institucional en los países en desarrollo. El trimestre económico, v. 59, n. 233, p. 23-64, 1992.

PEREZ, C. Technological revolutions and financial capital. Edward Elgar Publishing, 2003.

RODRICK, D. Industrial policy for the twenty-first century. John F. Kennedy School of Government, Harvard University, 2004.

RODRIK, D. Industrial development: some stylized facts and policy directions. Industrial development for the 21st century: sustainable development perspectives, Technical Report; United Nations Publications, p. 7-28, 2007.

SCHWAAG-SERGER, S. China's 15-year plan for scientific and technological development - a critical assessment. Asia Policy. Lund, p. 135-164. 2007.

SONG, L. State-owned enterprise reform in China: past, present and prospects. In: GARNAUT, R; SONG, L.; FANG, C. (eds.). China's 40 years of reform and development: 1978-2018. Australian National University Press, Camberra, p. 345-369, 2018.

VISENTINI, P. G. F. A novíssima China e o sistema internacional. Sociologia e Política, Curitiba, v. 19, p.131-154, 2011.

YU, B. Pattern of indigenous innovation: the case of HPEC[R]. Beijing: NSFC. 2007. 
ZHENG, Lu. O Caminho do desenvolvimento econômico chinês. In: BELLUCCI, B. Abrindo os olhos para a China. Rio de Janeiro: Educam, p. 75-99, 2004.

WORLD BANK, Banco de dados, 2019. Disponível em: https://data.worldbank.org/indicator/SI.POV.DDAY?locations=CN. Acesso em 15 de março de 2020. 